\title{
ASPECTOS TECNOLÓGICOS E PATENTÁRIOS DA RECUPERAÇÃO OU APROVEITAMENTO DE MATERIAIS POLIMÉRICOS RESIDUAIS NO BRASIL
}

\author{
D. S. CARVALHO ${ }^{1}$, D. A. SANTOS ${ }^{1,2}$, M. A. S. AGUIAR ${ }^{1}$ e A. J. LUNA $^{1}$ \\ ${ }^{1}$ Divisão de Polímeros - Instituto Nacional da Propriedade Industrial \\ ${ }^{2}$ Escola de Química - Universidade Federal do Estado do Rio de Janeiro \\ E-mail para contato: deysimar@inpi.gov.br
}

\begin{abstract}
RESUMO - Os polímeros estão cada vez mais presentes em nosso dia-a-dia, como materiais indispensáveis à vida moderna. No entanto, o descuido com o descarte atrai a atenção tanto pelas questões ambientais envolvidas, quanto por questões industriais devido à economia de energia e uso de matérias-primas "virgens". Sabe-se que para a harmônica condução de tais questões são necessários investimentos tecnológicos. No presente trabalho foram avaliados documentos patentários como fontes de informação tecnológica, industrial e mercadológica. Na presente análise, para o período entre 2007 a 2012, foram obtidos 159 documentos brasileiros no horizonte de 5962 documentos no mundo, a título de comparação no mesmo tempo foram 1239 documentos chineses. Os principais focos tecnológicos nacionais são: recuperação de aparas, incluindo reaproveitamento e reciclagem de pneus; e recuperação de polímeros em geral com ênfase na fabricação e usos de produtos reciclados de poliéster baseado em ácido tereftálico (PET).
\end{abstract}

\section{INTRODUÇÃO}

Nos dias de hoje, a reciclagem de polímeros é uma alternativa viável para minimizar o impacto ambiental causado pela disposição destes materiais em aterros sanitários ou de uma maneira inadequada no meio ambiente.

De acordo com Santos et al. (2005), aproximadamente 70\% dos resíduos sólidos estavam em aterros sanitários na Europa e EUA. No Japão, esta proporção ficava em torno de $40 \%$, pois grande parte foi usada para recuperação de energia. Dentre os materiais poliméricos mais nocivos destacam-se aqueles que contem cargas de metais pesados, plastificantes e os pneus. Estes por serem reticulados e não reprocessáveis, são os mais indesejados, devido ao elevado tempo de degradação e a problemas de saúde pública (Cossa et al., 2009; Jang et al.,1998; Pramanik et al. 1995; De et al, 2004). Dessa maneira, a recuperação/aproveitamento de sólidos poliméricos vem se tornando cada vez mais importante, pois além dos interesses ambientais e econômicos, começam a surgir legislações cada vez mais rígidas no sentido de minimizar e/ou disciplinar o descarte desses resíduos sólidos (Spinacé e De Paoli, 2005; Coltro e Duarte, 2013; NBR 13230, 2008).

Neste cenário, uma ferramenta que possibilita estudar o desenvolvimento de um determinado setor e contribuir para fundamentar o processo de análise do futuro da tecnologia é a prospecção tecnológica, que deve ser considerada como um monitoramento do 
desenvolvimento em uma área específica de interesse por meio de depósito de pedidos de patente, o qual pode ser realizado por meio de bases de dados. Entre as diversas bases de dados de patente disponíveis foi selecionada a base Espacenet ${ }^{\circledR}$ do European Patent Office (2014), conhecida também como EPODOC. Este banco de dados possui mais de 80 milhões de documentos de patentes em todo o mundo, contendo informações sobre invenções e desenvolvimentos técnicos de 1836 até os dias hoje.

O presente trabalho tem por objetivo oferecer uma visão do desenvolvimento da tecnologia de recuperação ou aproveitamento de materiais poliméricos residuais, utilizando-se do sistema de proteção por patentes no Brasil, por meio da técnica de monitoramento tecnológico, fazendo um levantamento, na base EPODOC, dos pedidos de patente relacionados a esta tecnologia. E, dessa forma, identificar o principal país e depositante detentor da tecnologia e mostrar a importância da proteção da invenção neste setor, bem como auxiliar na determinação do estado da técnica existente em termos de pesquisa e desenvolvimento tecnológico.

\section{METODOLOGIA}

A metodologia empregada foi baseada no monitoramento tecnológico usando a base EPODOC e realizada em 03 (três) etapas: (1) Elaboração de uma estratégia de busca para a recuperação dos documentos de interesse utilizando a Classificação Internacional de Patentes (CIP) considerando os anos de 1994 até 2014. A CIP escolhida para esse propósito foi todo o grupo B29B17 ("Recuperação por separação ou desintegração de matérias plásticas ou outros constituintes de material de refugo contendo matérias plásticas"), que contempla produtos reciclados de poliéster baseado em ácido tereftálico, polietileno, polipropileno, poliamidas, policarbonato, acrilonitrila-butadieno-estireno, policloreto de vinila, etc; (2) Utilização da mesma estratégia de busca da primeira etapa limitada de 2007 a 2012, considerando-se que um pedido de patente pode levar até 30 meses para ser publicado; (3) Disposição em tabelas dos dados obtidos na etapa (2), onde os dados bibliográficos dos pedidos de patentes recuperados tanto no Brasil como no mundo foram adequadamente interpretados. Nesta análise foram destacados, os seguintes dados: (i) número do pedido; (ii) dados da prioridade unionista (data, país e número); (iii) data de publicação do documento; (iv) CIP's; (v) resumo; (vi) título; (vii) nome do depositante e; (viii) nome do inventor.

\section{RESULTADOS E DISCUSSÃO}

A estratégia de busca utilizada recuperou um total de 31.490 documentos publicados no mundo, no período de 1994 a 2014, indexados sob as classificações: (i) B29B17/00; (ii) B29B17/02 e; (iii) B29B17/04 (Figura 1). A Figura 1 também apresenta uma análise comparativa da tendência de patenteamento de tecnologias relacionadas à recuperação ou aproveitamento de materiais poliméricos entre o mundo, o Brasil e a China no período de 1994 a 2014. No presente estudo, pode ser observado que no período de 2001 a 2008 houve uma queda no número de pedidos de patentes no mundo inteiro. Esse fato provavelmente pode ter sido influenciado por problemas decorrentes da crise econômica global de 2007, onde a Europa e a América estavam lutando para se recuperar desse impacto. Nesse aspecto, convém salientar que uma patente é um ativo econômico de proteção de direitos intangíveis e também está susceptível ao impacto de uma crise econômica. 


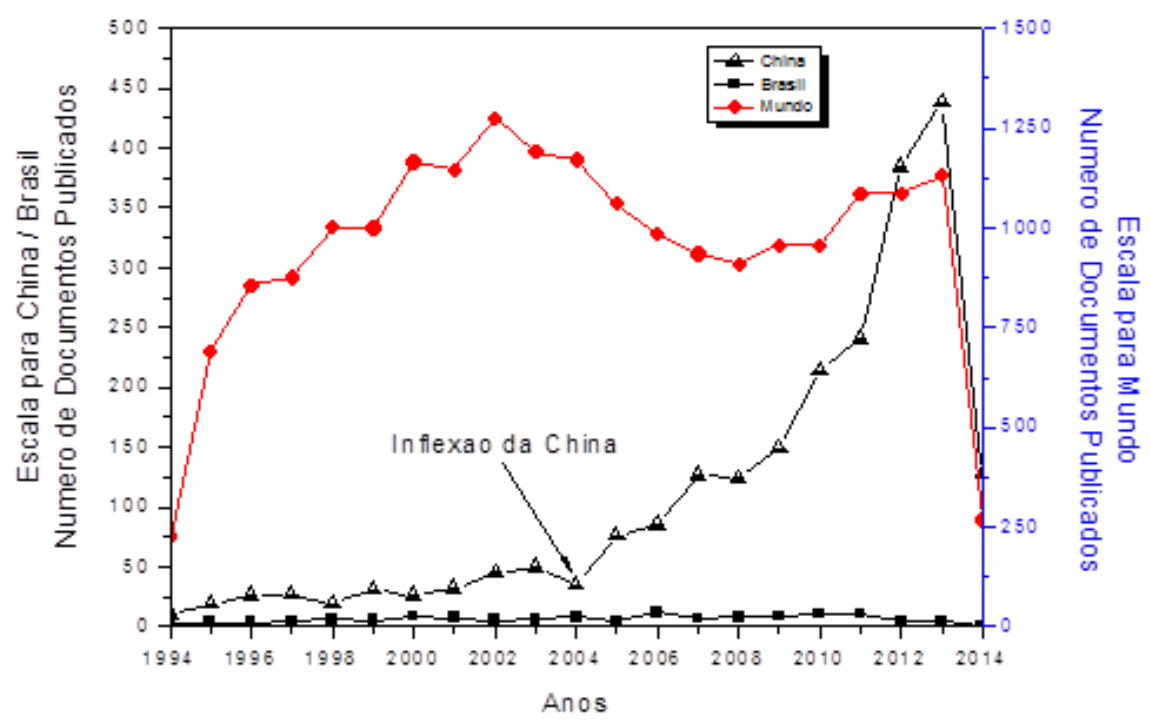

Figura 1 - Perfil de Distribuição Temporal das Publicações Patentárias relacionados à recuperação ou reaproveitamento de material polimérico.

Santos et al.(2011), em seus estudos sobre gestão do conhecimento aplicada à reciclagem de componentes automotivos, verificou uma tendência de redução no número de patentes no período entre 2001 e 2008. A partir disto e ainda considerando que: (a) ocorrências de crise na economia mundial no citado período; (b) o fato de que estes compostos são predominantemente derivados de petróleo; (c) as patentes são ativos intangíveis fortemente inter-relacionados com indicadores econômicos; depreende-se que tais variações durante o período de 2001 a 2008, diz respeito a reflexos das crises americana e europeia, aliado às fortes oscilações de preços do petróleo no mundo. Não obstante disto, observa-se também que há uma a tendência de crescimento dos depósitos de pedidos de patentes novamente a partir de 2009 após estabilização dos mercados (BP\&R, 2014).

Com relação ao Brasil observa-se que sua curva de desenvolvimento tem se comportado muito discretamente ao longo dos anos, tendo saltado de uma média de 15 para 22 pedidos de patentes por ano. Embora isso represente um aumento de cerca de 45\%, no entanto, em termos quantitativos ainda é muito pouco significativo quando comparado com outros países.

A avaliação dos países que patenteiam a tecnologia de recuperação e aproveitamento de polímeros residuais levou em consideração os principais países detentores da tecnologia tanto no período mais amplo (1994 a 2014) quanto no período de interesse (2007 a 2012). De acordo com a estratégia de busca da segunda etapa da metodologia foram obtidos 5962 documentos publicados no mundo, no período de 2007 a 2012, sob as mesmas CIPs, o que permite uma análise mais detalhada do desenvolvimento da tecnologia no período.

De acordo com a Tabela 1, observa-se que o Japão (JP) é o país que mais se destaca na busca por proteção para suas invenções, seguido pela China $(\mathrm{CN})$ no período de maior abrangência. Entretanto, tomando por base o período de 2007 a 2012, observa-se uma inversão de posição entre estes países. Isso mostra que a China tem se desenvolvido cada vez mais nesta tecnologia procurado proteger suas invenções, sendo responsável por $28 \%$ dos 
pedidos de patentes recuperados no período de 2007 a 2012. Com relação ao Brasil, nota-se que o mesmo vem evoluindo lentamente nessa temática, saindo da $11^{\mathrm{a}}$ para a $10^{\mathrm{a}}$ posição.

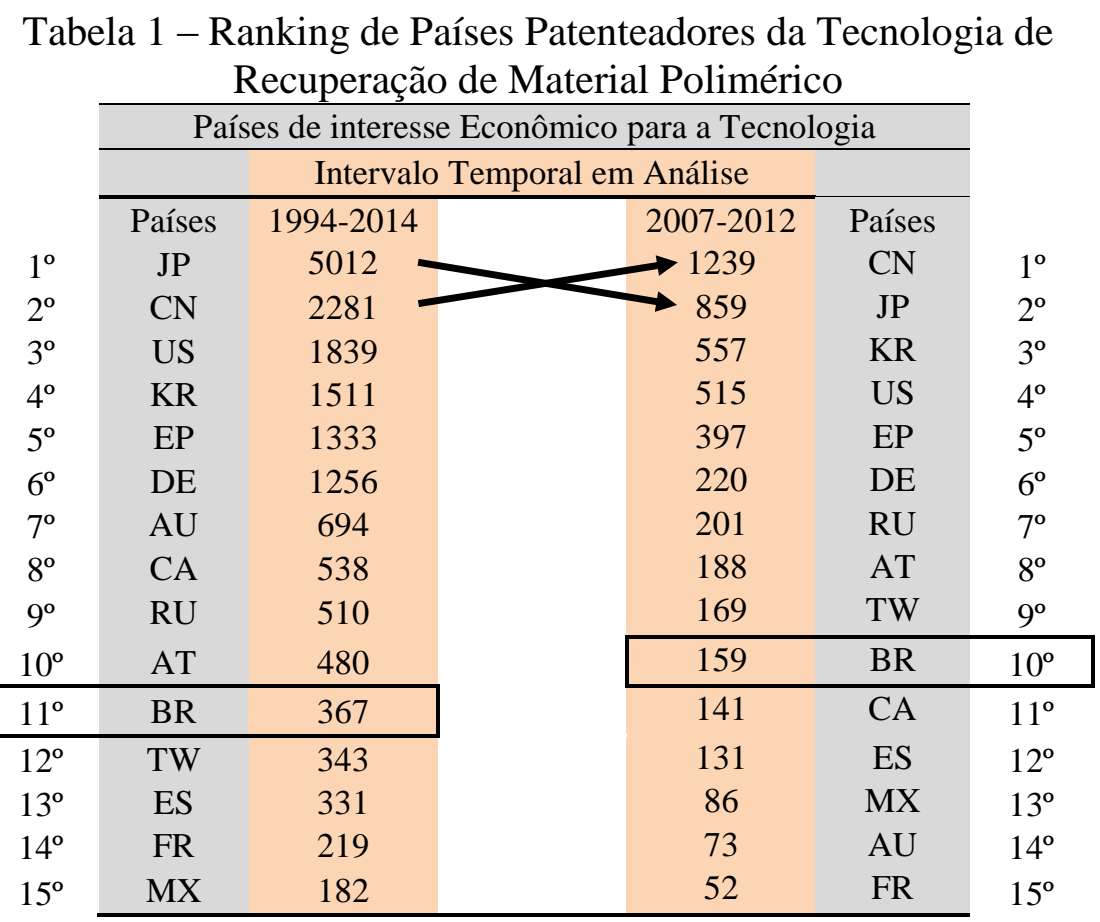

Dentre os países que se destacam na busca por proteção para suas invenções à China vem ganhando cada vez mais destaque, principalmente a partir de 2004, como pode ser visto na Figura 1 e Tabela 1. Embora a China tenha estado sempre entre os principais mercados de interesse para proteger as invenções relacionadas à tecnologia de recuperação ou aproveitamento de materiais poliméricos, observou-se que até 2004 (inflexão da China) o número de documentos patentários por ano evoluiu lentamente. Entretanto, a partir de então, nota-se claramente um salto crescente no número de pedidos de patentes depositados na China. Uma explicação plausível para a preocupação da China quanto à proteção patentária parece residir nos acontecimentos pré-crise econômica.

Coggiola (2012), em seus estudos sobre a crise econômica de 2007 a 2012 relatou que a China, foi vista como remédio para a tendência de estagnação econômica mundial. O acordo comercial da China com os EUA, de 1999, definiu mais claramente via inserção do país no mercado mundial na sua nova etapa econômica. O mercado de capitais da China expandiu-se o dobro que o PIB entre 1993 e 2004 e o PIB chinês cresceu quase $90 \%$ entre 2000 e 2005, com um crescimento da renda anual per capita de 930 para 1740 dólares no mesmo período.

Em que pese o crescimento chinês, e de outros "países emergentes" o processo desigual de desenvolvimento científico e tecnológico entre as nações continuou e, em áreas decisivas, até se ampliou, conforme Coggiola (2012). Essa assertiva pode ser confirmada no presente trabalho pela verificação do registro dos percentuais mundial de patentes mostrados na Tabela 1, mais particularmente, para a área de tecnologia de polímeros.

Em parte, o acentuado número de documentos patentários publicados justifica-se pelo investimento na área de pesquisa e inovação tecnológica (P\&D). De acordo com Coggiola 
(2012), em 2004 havia 107 centros independentes de P\&D de multinacionais na China; em 2010, eles já somavam 1.100. Com esses avanços, a China passou a competir com os países desenvolvidos, já tendo inclusive deixado o Japão para trás como um dos países patenteadores da tecnologia de recuperação de matérias plásticas no período de 2007-2012. O Brasil, por sua vez, se mantém num patamar numérico bastante inferior à China.

Buscando harmonizar os critérios patentários de acordo com a etapa (2) da metodologia, analisou-se o período temporal da Tabela 1 restringindo a cinco anos de patenteamento a contar de 2007 até 2012, dando foco na China como líder e no Brasil que vem evoluindo lentamente na temática. Desta forma, a análise temporal comparativa do período de 2007 a 2012 revela que dos 5962 documentos de patentes publicados no mundo, 1.239 (21\%) foram depositados na China, mostrando que este é um mercado de forte interesse para esta tecnologia. Por outro lado, apenas 159 (3\%) buscaram proteger suas invenções no Brasil. Este resultado sugere não haver interesse dos países detentores da tecnologia em protegê-las no Brasil. No caso do próprio Brasil, supõe-se que a cultura da proteção patentária seja ainda incipiente (Tabela 1).

A Figura 2 apresenta um perfilamento da procedência dos documentos patentários publicados no Brasil. Dos 159 documentos publicados no Brasil, 27 (16,98\%) ocorreram via PCT (Tratado de Cooperação em Matérias de Patentes), 29 (18,24\%) foram via CUP (Convenção da União de Paris) e 103 (64,78\%) foram nacionais (publicações endógenas residentes). Dos 103 documentos patentários nacionais, $86(83,5 \%)$ correspondem a pedidos de patentes de invenção (PI) e 17 (16,5\%) corresponde a pedidos de modelo de utilidade.

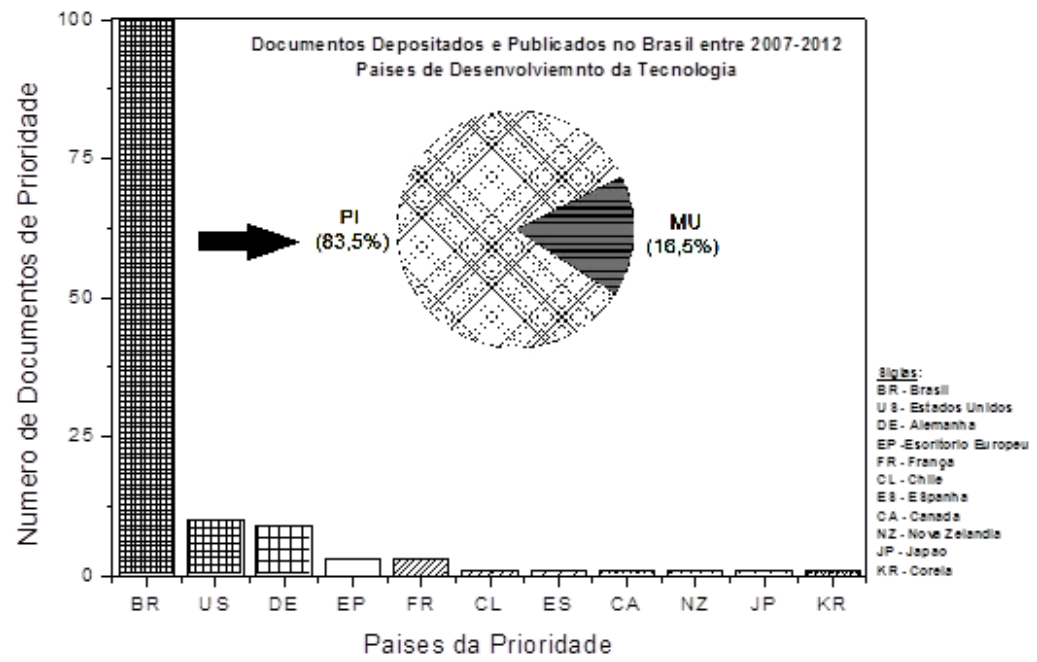

Figura 2: Perfil de Distribuição dos Documentos de Prioridade. Em Destaque, o Percentual dos Pedidos em Função da Natureza do Depósito.

A Figura 2 também mostra quais são os países que se destacam na busca por proteção para suas invenções relacionadas à tecnologia de recuperação de matérias plásticas e material de refugo contendo matérias plásticas no Brasil. O Brasil é, notadamente, o país que mais se destaca em proteger esta tecnologia no seu território. Em seguida, têm-se os Estados Unidos (US) seguido da Alemanha (DE). O resultado encontrado mostra que o principal interessado em proteger sua tecnologia no mercado brasileiro é o próprio Brasil, enquanto que outros países, como os Estados Unidos e a Alemanha não têm demonstrado um forte interesse em 
proteger sua tecnologia no mercado brasileiro.

A Tabela 2 revela diferentes focos tecnológicos para os documentos recuperados nos âmbitos: (i) Mundo; (ii) China; (iii) Brasil. A subclasse B29B17 foi retirada desta análise por se tratar da CIP foco da busca, portanto seria óbvio esperar que a maioria dos documentos fossem desta categoria tecnológica. Nesse contexto, os documentos depositados no Brasil tiveram como principais características tecnológicas (foco tecnológico): recuperação de aparas, incluindo reaproveitamento e reciclagem de pneus e polímeros reciclados e fabricação e usos de produtos reciclados de poliéster baseado em ácido tereftálico (garrafas PET). Ao menos 30 documentos envolviam o uso de polímeros de poliéster baseado em ácido tereftálico. Além disso, dos 159 documentos BR analisados 135 documentos utilizaram nessa recuperação e reciclagem métodos de trituração, corte, pulverização e granulação do material polimérico tal como também observado por Santos et al. (2011).

Tabela 2 - Focos Tecnológicos Observados nas Publicações Patentárias para o Mundo, China e Brasil nos últimos 5 anos (2007-2012)

\begin{tabular}{|c|c|c|c|}
\hline $\begin{array}{l}\text { Mundo: } \\
\text { Posição }\end{array}$ & Frequência & CIP & Descrição \\
\hline 1 & 879 & C08J11 & $\begin{array}{l}\text { Recuperação ou aproveitamento de polímeros residuais sem reações } \\
\text { químicas usando solventes seletivos para os componentes do polímero ou } \\
\text { pelo tratamento exclusivo de calor seco }\end{array}$ \\
\hline 2 & 789 & B09B3 & $\begin{array}{l}\text { Reaproveitamento ou recuperação de polímeros residuais contidos no lixo } \\
\text { sólido pela destruição ou transformação do material polimérico em algo de } \\
\text { útil ou inofensivo }\end{array}$ \\
\hline 3 & 587 & $\mathrm{~B} 02 \mathrm{C} 18$ & $\begin{array}{l}\text { Desintegração de polímeros residuais por facas tipo rotativas dentro de } \\
\text { recipientes ou outros elementos de cortar ou rasgar que transformam o } \\
\text { material polimérico em fragmentos - granulação ou picotamento }\end{array}$ \\
\hline 4 & 108 & B29B9 & $\begin{array}{l}\text { Fabricação de grânulos pela divisão de material pré-formado na forma de } \\
\text { material filamentar, p. ex., combinado com extrusão }\end{array}$ \\
\hline $\begin{array}{l}\text { China: } \\
\text { Posição }\end{array}$ & Frequência & CIP & Descrição \\
\hline 1 & 404 & $\mathrm{~B} 02 \mathrm{C} 18$ & $\begin{array}{l}\text { Desintegração de material polimérico residual por facas ou outros } \\
\text { elementos de cortar ou rasgar que transformam o material em fragmentos } \\
\text { com facas rotativas dentro de recipientes horizontais, com ênfase em: (i) } \\
\text { Facas e suas montagens; e, (ii) Formas de Acionamentos; }\end{array}$ \\
\hline 2 & 156 & B09B3 & $\begin{array}{l}\text { Reaproveitamento ou recuperação de polímeros residuais contidos no lixo } \\
\text { sólido pela destruição ou inertização do material polimérico; }\end{array}$ \\
\hline 3 & 55 & $\mathrm{C} 08 \mathrm{~J} 11$ & $\begin{array}{l}\text { Recuperação ou aproveitamento de polímeros residuais sem reações } \\
\text { químicas usando solventes seletivos para os componentes do polímero ou } \\
\text { pelo tratamento exclusivo de calor seco; }\end{array}$ \\
\hline 4 & 51 & B29B9 & $\begin{array}{l}\text { Fabricação de grânulos pela divisão de material pré-formado na forma de } \\
\text { material filamentar, p. ex., combinado com extrusão; }\end{array}$ \\
\hline $\begin{array}{l}\text { Brasil: } \\
\text { Posição }\end{array}$ & Frequência & CIP & Descrição \\
\hline 1 & 40 & $\mathrm{C} 08 \mathrm{~J} 11$ & $\begin{array}{l}\text { Recuperação ou aproveitamento de polímeros residuais sem reações } \\
\text { químicas usando solventes seletivos para os componentes do polímero ou } \\
\text { pelo tratamento exclusivo de calor seco; }\end{array}$ \\
\hline 2 & 9 & B29B11 & Fabricação de pré-formados por injeção ou extrusão; \\
\hline 3 & 8 & B29B9 & $\begin{array}{l}\text { Fabricação de grânulos pela divisão de material pré-formado na forma de } \\
\text { material filamentar, p. ex., combinado com extrusão; }\end{array}$ \\
\hline 4 & 5 & B09B3 & $\begin{array}{l}\text { Reaproveitamento ou recuperação de polímeros residuais contidos no lixo } \\
\text { sólido pela destruição ou inertização do material polimérico. }\end{array}$ \\
\hline
\end{tabular}


A Tabela 3 apresenta os principais depositantes de documentos patentários no mundo no período entre 2007 e 2012, enquanto a Tabela 4 apresenta os principais depositantes de documentos patentários no Brasil, considerando o mesmo período.

Tabela 3 - Principais Depositantes Patentários no Mundo entre 2007 e 2012

\begin{tabular}{cclc}
\hline Posição & Frequência & \multicolumn{1}{c}{ Depositante } & Procedência \\
\hline 1 & 282 & EREMA & Alemanha \\
2 & 98 & KRONES AG & Alemanha \\
3 & 52 & MITSUBISHI ELECTRIC CORP & Japão \\
4 & 52 & XYLECO INC & Estados Unidos \\
5 & 50 & CVP CLEAN VALUE PLASTICS GMBH & Alemanha \\
\hline
\end{tabular}

Observa-se que apesar da China ser a maior detentora de patentes no período entre 2007 a 2012 não há "clusters" ou monopolização de empresas chinesas. Há sim uma dispersão da proteção da propriedade industrial para empresas advindas da China. $\mathrm{O}$ principal depositante a nível mundial é a Erema, uma empresa alemã. Já no Brasil (Tabela 4), no mesmo intervalo temporal, os maiores protetores da tecnologia são depositantes nacionais distribuídos entre individuais e universidades/fundações.

Tabela 4 - Principais Depositantes Patentários no Brasil entre 2007 e 2012

\begin{tabular}{cclc}
\hline Posição & Frequência & \multicolumn{1}{c}{ Depositante } & Procedência \\
\hline 1 & 5 & KRONES AG & Alemanha \\
2 & 3 & CVP CLEAN VALUE PLASTICS GMBH & Alemanha \\
3 & 3 & CARLO MARCONE SILVA RABELO & Brasil \\
4 & 2 & ADRIANO DAVID & Brasil \\
5 & 2 & EDILSON CELESTINO FERREIRA & Brasil \\
6 & 2 & FAPESP-FUND. AMP. PESQ. SÃO PAULO & Brasil \\
7 & 2 & M \& G POLIMERI ITALIA SPA & Itália \\
8 & 2 & UNIV RIO DE JANEIRO & Brasil \\
\hline
\end{tabular}

\section{CONCLUSÕES}

A análise de patentes fornece informações úteis sobre vários aspectos da gestão de tecnologia e o monitoramento de área em termos de produtos e processos. O uso desta ferramenta no presente trabalho corroborou as expectativas de se obter uma visão do desenvolvimento da tecnologia de recuperação ou aproveitamento de materiais poliméricos residuais desde um referencial em que se avaliaram as tendências tecnológicas mundiais no setor da classificação B29B17, até finalmente, focalizar nos aspectos tecnológicos dos desenvolvedores de tecnologia em território nacional.

Neste cenário, observou-se que o interesse por este nicho tecnológico se faz presente no mundo em anos recentes. Contudo, verificou-se que houve variações no número dos documentos patentários publicados entre os anos de 2001 e 2008. Sugere-se que tal fenômeno tenha sido ocasionado por sucessivas crises econômicas mundiais, em especial as crises americana e europeia, aliado às fortes oscilações de preços do petróleo no mundo no mesmo período.

Um extrato realizado para o período entre 2007 a 2012 revelou uma paisagem dentre os desenvolvedores de tecnologia distinta daquela que veio se formando desde 1994. Neste contexto, verificou-se que a China deu uma reviravolta tecnológica se destacando no cenário 
mundial, mesmo com a crise econômica ocorrida no mundo a partir de 2007. Em contraste com o cenário mundial e chinês, o número de publicações com prioridade brasileira mantevese pouco expressivo e com variação nos depósitos incipiente, apresentando como principais características tecnológicas: recuperação de aparas, incluindo reaproveitamento e reciclagem de pneus; e reciclagem de polímeros à base de produtos reciclados de poliéster baseados em ácido tereftálico (garrafas PET) - fabricação e usos.

\section{REFERÊNCIAS}

ASSOCIAÇÃO BRASILEIRA DE NORMAS TÉCNICAS - ABNT. NBR 13230: Embalagens e acondicionamentos plásticos recicláveis - identificação e simbologia, Rio de Janeiro, 8p., 2008.

BRITISH, PLASTIC AND RUBBER - BP\&R. Polymer raw material prices: 2012 Review and 2013 Outlook. Disponível em: http://www.britishplastics.co.uk/materials/polymer-rawmaterial-prices\%3A-2012-review-and-2013-outlook/.

COGGIOLA, O. A crise (2007-2012): Lineamentos para uma abordagem global. Aurora, Marília, v.6 (1), p. 175-382, 2012. Disponível em:

http://www2.marilia.unesp.br/revistas/index.php/aurora/article/view/2704/2127.

COLTRO, L.; DUARTE, L. C. Reciclagem de embalagens plásticas flexíveis: contribuição da identificação correta. Polímeros, v. 23 (1), p. 128-134, 2013.

COSSA, M. M.; SIRQUEIRA, A. S.; SOARES, B. G. Desenvolvimento de Elastômeros termoplásticos vulcanizados (TPV) a base de polipropileno com resíduo de pneu: I Planejamento Fatorial de Experimentos. Polímero-Ciência e Tecnologia, v. 19, (3), p. 190195, 2009.

DE, S. K.; ISAYEV, A.; KHAIT, K. Rubber Recycling. CRC Press, 528 p., 2004.

EUROPEAN PATENT OFFICE. Espacenet - Patent Search. Disponível em: http://www.epo.org/searching/free/espacenet.html. Acesso em: 24 de março, 2014.

JANG, J. W.; YOO, T. S.; OH, J. H.; IWASAKI, I. Discarded tire recycling practices in the United States, Japan and Korea. Resources, Conservation and Recycling, v. 22 (1-2), p.1-14, 1998.

PRAMANIK, P. K.; BAKER, W. E. Toughening of ground rubber tire filled thermoplastic compounds using different compatibilizer systems. Plast. Rubber Comp. Process Appl., v. 24, p.229, 1995.

SANTOS, A. da S.; SANTOS, L. de S.; SOUZA, R. C. A gestão do conhecimento aplicada à reciclagem de componentes automotivos através do tratamento das informações contidas em documentos de patentes. Química Nova, v. 34 (5), p. 905-909, 2011.

SPINACÉ, M. A. da S.; De PAOLI, M. A. A Tecnologia da Reciclagem de Polímeros. Química Nova, v. 28 (1), 2005. 